\title{
Effectiveness of Modern Teaching Methods; Evidence from Digital Learning Model of Modern Teaching Methods
}

\author{
Ejaz Gul \\ Bahauddin Zakariya University, Multan, Pakistan \\ ejazgul@bzu.edu.pk
}

\begin{abstract}
This paper elucidates the efficacy of three selected modern and innovative methods of learning by taking a group of 80 students of economics class at university level. Their opinion regarding three selected modern teaching methods was obtained through a questionnaire and statistical analysis of their opinion was carried out which indicated strong tendency towards mutual practice method as 40 out of 80 students (50\%) declared it as very effective method of learning in the practice stage. On the other hand, 30 students (37.5\%) opined that controlled practice method is moderately effective and 28 (35\%) students opined that team practice method is slightly effective. After this analysis, students were put to practically learn use of econometric software 'E Views' through the same three selected methods. The digital model for their learning process was created using Computer Assisted Qualitative Data Assisted Software (CAQDAS). The statistical analysis of students' opinion and digital analysis of practical learning process indicated that mutual practice is the most effective method of practice. It is because students learn better and fast when they are allowed to use their initiative and judgment. At the end, guidelines for effective teaching have been suggested.
\end{abstract}

Keywords: Learning, modern, teaching, methods, students, opinion, statistical, analysis, digital, model

\section{Introduction}

Sound learning is highly dependent on method of teaching. Modern teaching methods signify the active role of both teacher and students. Students are no more the passive part of teaching. Now, the traditional role of teacher has been changed to a mentor or guide while students assume active role in learning process. Learning has become interplay of both teacher and students focusing on their dynamism. In the modern teaching methods, students are actively involved in the whole activity of teaching and they learn through understanding and practices. Practice stage of learning is particularly focused in the modern teaching methods as it culminates the learning activity. After the practice stage of leaning, student is supposed to have full grip on the phenomenon being taught. The modern teaching methods being used in the developed world enlist many techniques for the practice stage of learning but in this paper the efficacy of three methods was determined based on the opinion of a group of 80post graduate (M.Phil.) students of School of Economics, Bahauddin Zakariya University. These three methods were controlled practice, mutual practice and team practice methods. The statistical analysis of data was carried out which was validated by digital analysis of the actual learning process by these three methods of practice. In essence, this paper describes three innovative practice methods and gives a clear picture of the efficacy of these methods empirically and digitally.

\section{Literature Review}

Modern behavioral and educational scientists agree on the point that learning is a systematic process comprising definite stages and action within each stage. Modern educational scientists like Adam has simplified the process and have summarized that there are three stages in learning a phenomenon; building stage, development stage and practice stage (Adam, 2002). Leaning ladder according to modern education theory is shown in Figure 1. The same model was clarified by Birdsall his works as he explained that theoretical teaching is only done in the building stage which is the stage with least time. The understanding of phenomenon is developed in the development stage, whereas learning is perfected in the practice stage (Birdsall, 2005). Similarly Broadhead has emphasized that the involvement and engagement of teacher should ideally reduce gradually from building to practice stage (Broadhead, 2010). Corts has explained that practice stage is the most important stage as it culminates the learning process. Therefore, practice stage of 
learning is being focused extensively by educationists across the globe (Corts, 2000). A modern educationist like Fabian has emphasized the use of initiative and judgment by students during practice stage of learning (Fabian, 2009). But, mostly it is not so in the traditional methods of teaching being adopted in the under developed and developing countries. In these countries, teacher is still the active part of learning even in practice stage which is contrary to the modern approach of teaching. Ives has explained that in modern teaching methods, learning is through active participation of students while teacher acts as a mentor or guide (Ives, 2001). For the practice stage of learning, three methods are being extensively in the developed world; controlled practice method, mutual practice method and the team practice method as shown in Figure 2.

Figure 1: Leaning ladder according to modern education theory

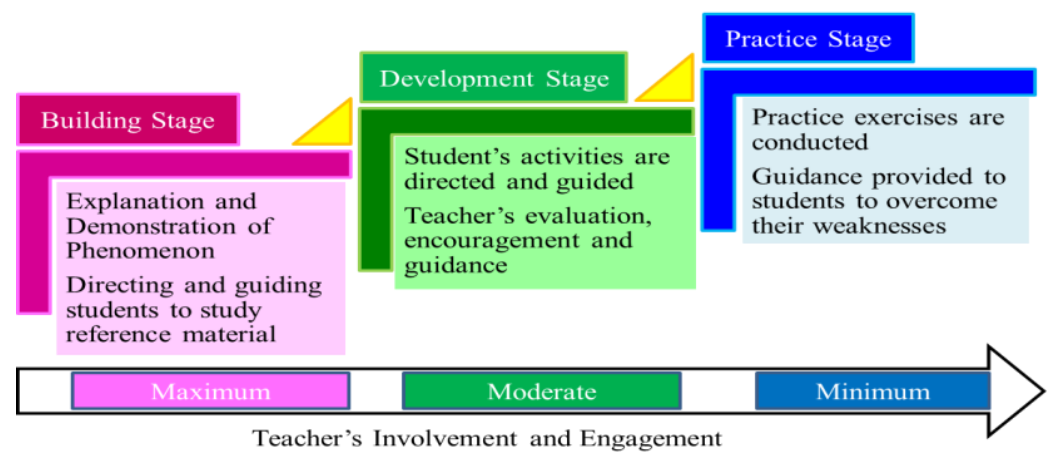

Figure 2: Three modern methods for learning in the practice stage

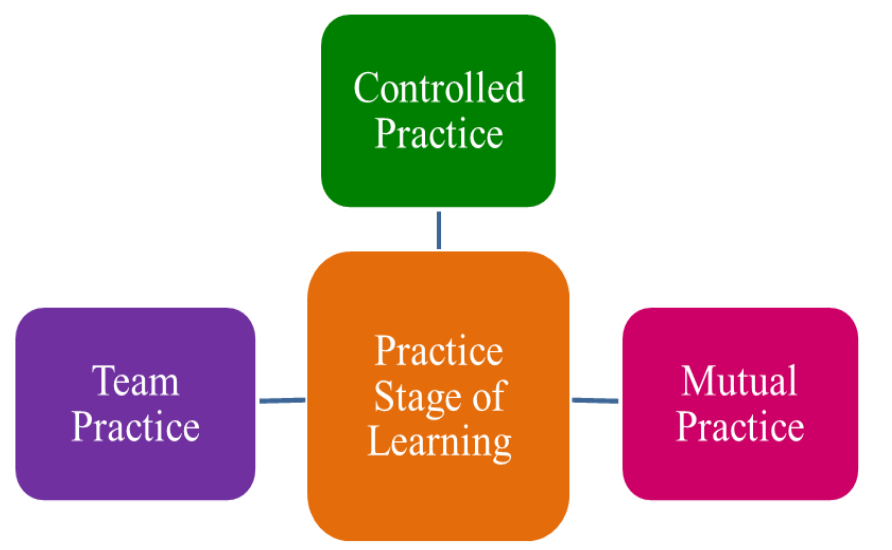

In controlled practice method, students work individually or collectively under the supervision of a teacher. As per Jonassen teacher is the active part in controlled practice approach (Jonassen, 2000). Jones has identified that in controlled practice method students are not allowed to initiate their actions and use their judgment beyond certain limits. Students work in accordance with guidance and direction given by teacher. They work with the teacher step by step and learn the phenomenon under supervision of the teacher (Jones, 1999).In controlled practice method, practical activity is conducted entirely under the supervision of a teacher and students remain passive as they are allowed to use pre-determined steps to go through the practice stage. Mutual Learning Method is being used extensively in the developed world. In this method, a phenomenon is taught and then students are allowed for supervising each other's work under the limited guidance of the teacher. As explained by Lin, the students alternatively act as coach and pupil (Lin, 2002). In this method students think as well as do. As explained by Siraj, it stimulates interest and builds up a sense of responsibility and spirit of cooperation. In this method of learning, teacher is relatively passive and students are active (Siraj, 2008). Sylva has indicated that in this method of practice students are allowed to initiate their actions and use their judgment. Students learn better when they are at their own under the guidance of a teacher with least involvement (Sylva, 2006). In modern context, a teacher should just act as mentor and guide the students, rather controlling them and not allowing them to use their judgment. In Team learning method students are first trained individually and then made part of a team. Teven has elucidated that in this 
method, they learn how to work with others and in the process learn a phenomenon. Each team is sequentially supervised and guided by teacher. Students use their initiative and judgment after approval of the teachers (Teven, 1997). As explained by $\mathrm{Wu}$, team practice is done in two phases, the theoretical phase and the practical phase (Wu, 1987). Wood has elucidated that in theoretical phase, the members of the team, students learn the phenomenon theoretically. In practical phase, the whole team masters the phenomenon collectively under a practical scenario. Teacher remains active in both the phases (Wood, 2005).

Key Contributions of this Study: Many researchers have worked on the efficacy of modern teaching methods, however, empirical evidence based on student's opinion, digital analysis and realistic learning index is not available in literature. Therefore, this study has contributed manifold to the subject. Key contributions are listed below.

- A factual study on the students under realistic environment.

- Digital analysis of student's opinion with the help of computer assisted qualitative data analysis software (CAQDAS). The digital learning curves and related equations were really revealing and meaningful. Use of digital software in analysis of primary data is a new paradigm introduced by this paper.

- Calculation of realistic learning indexes (LIs) for students 'learning using Newton-Leibniz integration process.

\section{Methodology}

It was not a simple task to determine the best method for efficient learning in practice stage of learning as different methods may suit different environments. Educationists have given divergent verdicts about the suitability of various practice methods. To accomplish this task, a thorough research methodology was used which comprised following steps.

- Step 1: Literature review of the modern teaching methods was carried out to know conceptual aspects and applicability of these methods. This has already been explained in section 2 .

- Step 2: Students' opinion was gathered though a simple questionnaire which was distributed into 80 students. Each student was required to answer the four simple questions about suitability of each method.

- Step 3: Statistical analysis of the primary data obtained from students was done to determine the best method for practice stage of learning.

- Step 4: Validation of the best practice method by digital modeling of learning process using computer assisted qualitative data analysis software (CAQDAS).

- Step 5: Based on experience and discussion with experts, guidelines have been deduced for successful teaching.

A simple random sample of 80 postgraduate (M.Phil.) students from School of Economics, Bahauddin Zakariya University was selected as respondents regardless of gender, caste and creed. The sample configuration was kept mixed. It included students from all categories. The mixed representation in the sample catered for bias and error in the sampling. 35 out of 80 students (43.75\%) were females. Average age of the students was 20 years. An interactive and easy to follow questionnaire was designed to gather the opinion of these 80 students about best practice method. Each student was required to answer four simple questions about each technique, whether that technique is slightly effective, moderately effective, very effective or not effective at all. They Students were given full liberty to answer as per their own assessment. The data obtained through questionnaire was statistically analyzed and results were obtained. To validate the results, students were given the assignment of learning econometric software "E-Views" with different practice methods. Digital models for each method were created with computer assisted qualitative data analysis software (CAQDAS). The results from students' opinion and digital models were compared and conclusions were drawn. When this process was completed, students were found much learned, and their opinion was validated empirically and digitally. The complete scheme of data collection and anlysis is elucidated in Figure 3. 
Figure 3: Scheme of data collection and analysis

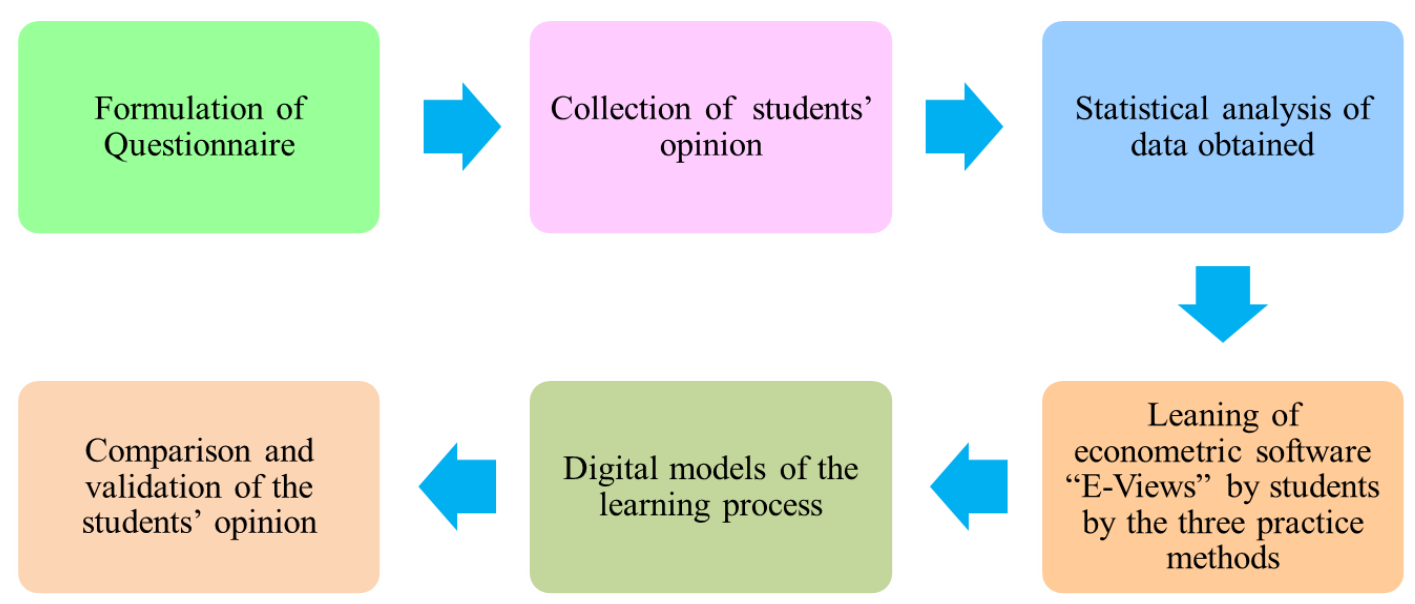

\section{Results}

Statistical Analysis of Data: The feedback was obtained from 80 students through questionnaire as shown in Table 1. Students expressed their opinion about different methods openly as per their as own judgment. The data obtained along with descriptive statistics is shown in Table 1 . The statistical analysis reflects a very interesting scenario of the student's opinion. Few statistical conclusions from the data shown in Table 1 are as under.

- The standard deviation value for mutual practice was high (12.50), followed by team practice (7.54) and then controlled practice (7.50). Statistically it means that for mutual practice technique, the change in opinion occurred after every 12th student, whereas in case of controlled and team practice techniques, every 7 th or 8th student changed his or her opinion.

- Data set of mutual practice had positive skewness which meant that its data contained few small values. This again proved that students are satisfied with the mutual practice. On the other hand, controlled and team practice methods had negative skewness, which indicated that its data contained few high values. It reflected that students were not satisfied with the controlled practice and team practice.

- Data set for mutual practice had positive kurtosis value, indicating that curve represented by data set was steeper than normal distribution curve and most of the observations were clustered near average and fewer on extremes. On the other hand, data set for controlled and team practice had negative kurtosis value indicating a flatter curve than normal distribution curve. In other words, fewer observations clustered near average and more observations populated on extremes.

Table 1: Summary of the data obtained through questionnaire

\begin{tabular}{llll}
\hline Students Response & $\begin{array}{l}\text { Methods } \\
\text { Number of Students for } \\
\text { Controlled Practice }\end{array}$ & $\begin{array}{l}\text { Number of Students } \\
\text { for Mutual Practice }\end{array}$ & $\begin{array}{l}\text { Number of Students } \\
\text { for Team Practice }\end{array}$ \\
\hline Not effective & 10 & 7 & 12 \\
Slightly Effective & 20 & 15 & 28 \\
Moderately Effective & 30 & 18 & 23 \\
Very Effective & 20 & 40 & 17 \\
Descriptive Statistics & & & \\
Average & 20 & 20 & 20 \\
Standard Deviation & 7.5 & 12.5 & 7.54 \\
Kurtosis & -3.9 & 0.93 & -3.64 \\
Skewness & -0.37 & 0.56 & -0.31 \\
\hline
\end{tabular}


Figure 4: Graphical representation of the data

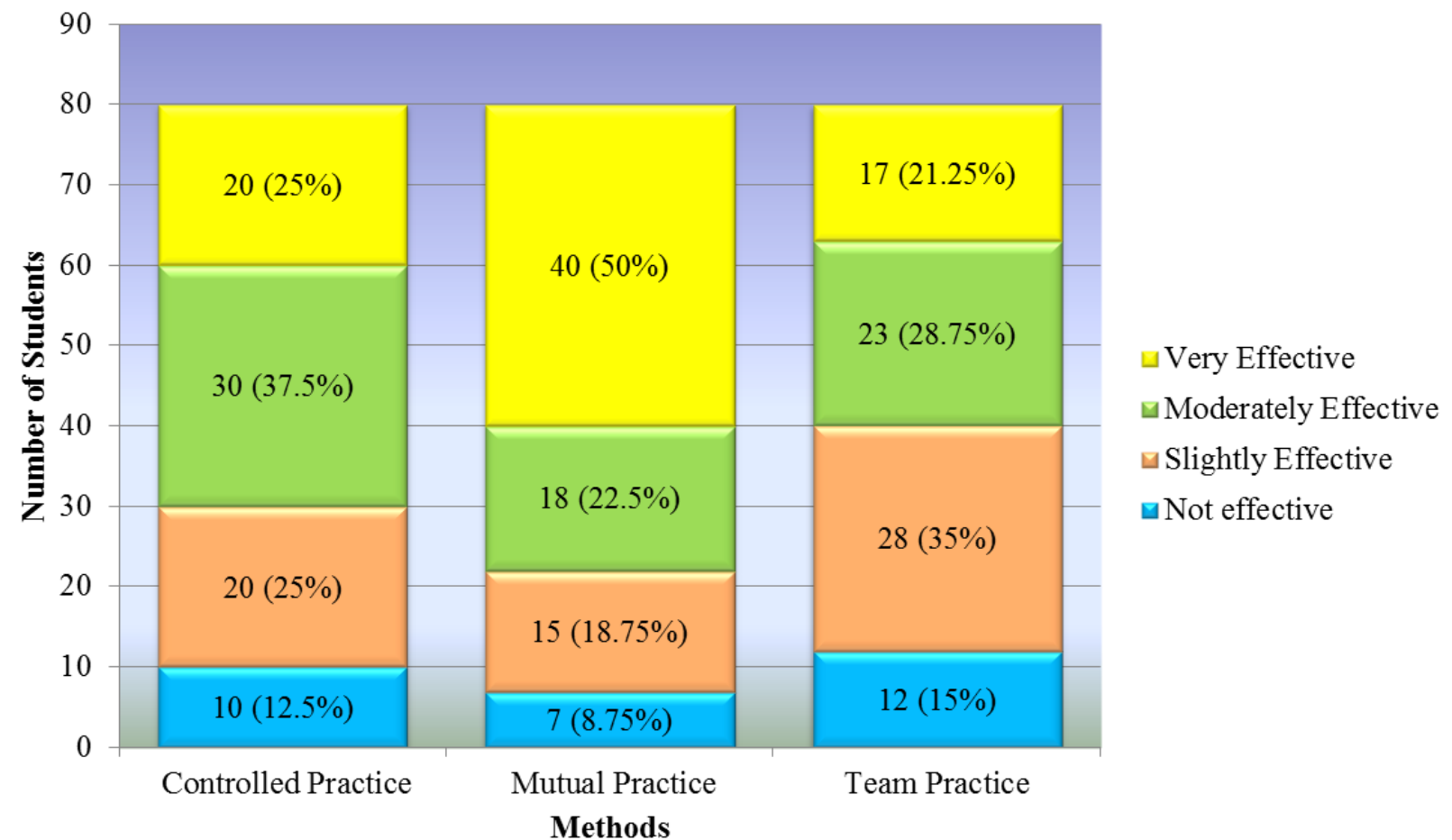

The graphical representation of data in Figure 4 indicated strong tendency towards mutual practice method as 40 out of 80 students (50\%) declared it as very effective method of learning in the practice stage. On the other hand, 30 students $(37.5 \%)$ opined that controlled practice method is moderately effective and 28 (35\%) students opined that team practice method is slightly effective. This showed that students like initiative and use of judgment which is optimally available in mutual practice method.

Digital Modeling of Learning Process: After determining the best method based on students' opinion, students 'opinion was validated by assigning them to learn Econometric Software "E-Views" by the three practice methods. Controlled practice was carried out by complete 80 students under direct supervision of the teacher. While for mutual and team practice methods, students were divided into 5 groups of 16 students each randomly with mixed representation. Each group was allowed 15 practices to learn the handling of software. The methodology adopted is shown in Figure 5.

\section{Figure 5: Methodology for validation of students' opinion}
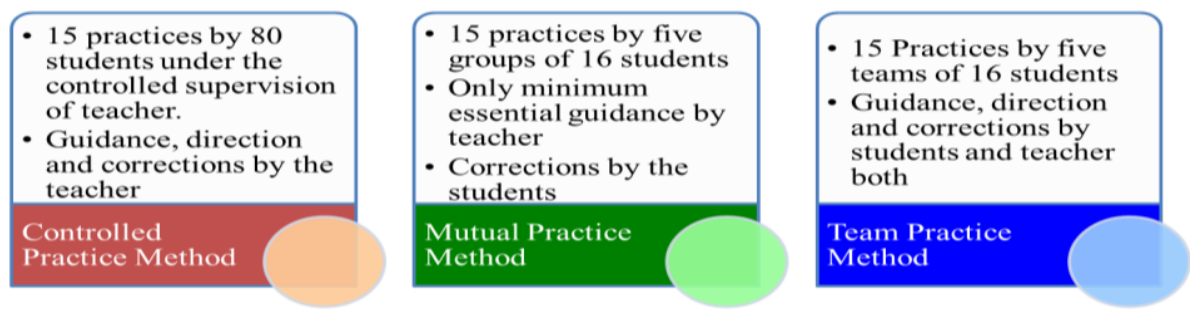

During the practice stage, students were observed closely and their learning proficiency and improvement after each practice was carefully noted. They were mentored in the mutual and team practice methods while they were taught and demonstrated in the controlled practice method. Thus, a very definite relationship between number of practices by students and percentage skill development was obtained for all the three methods. After completion of 15 practices by students, they were segregated into four categories as per their learning proficiency i.e. $25 \%, 50 \%, 75 \%$ and $100 \%$ learning proficiency. The desired proficiency of each category is shown in Figure 6. 
Figure 6: Categories of learning proficiency after 15 practices by students

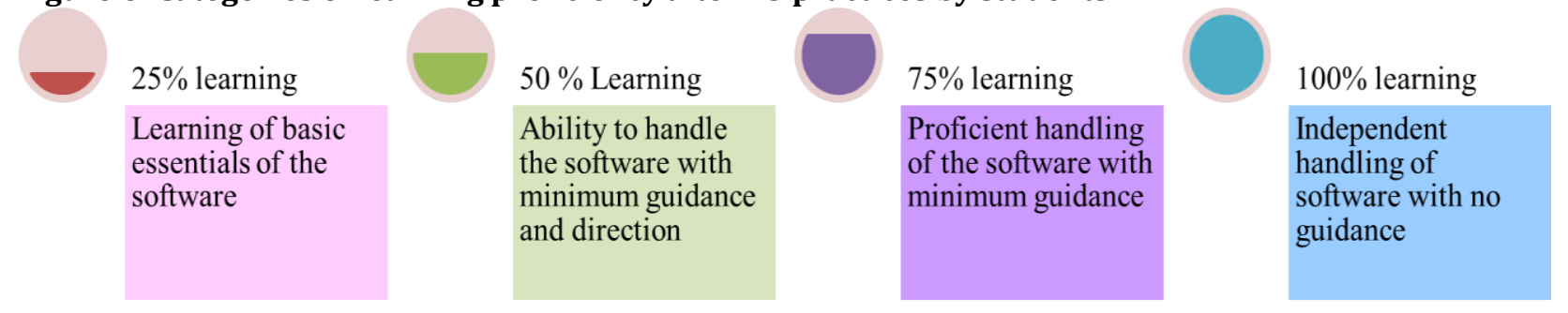

The data was shifted to computer assisted qualitative data analysis software (CAQDAS) and digital model of the learning process by three methods were developed which is shown in Figure 7. CAQDAS is versatile software and is being used by social scientists around the globe for analysis of qualitative data.

\section{Figure 7: Digital model of learning by three practice methods}

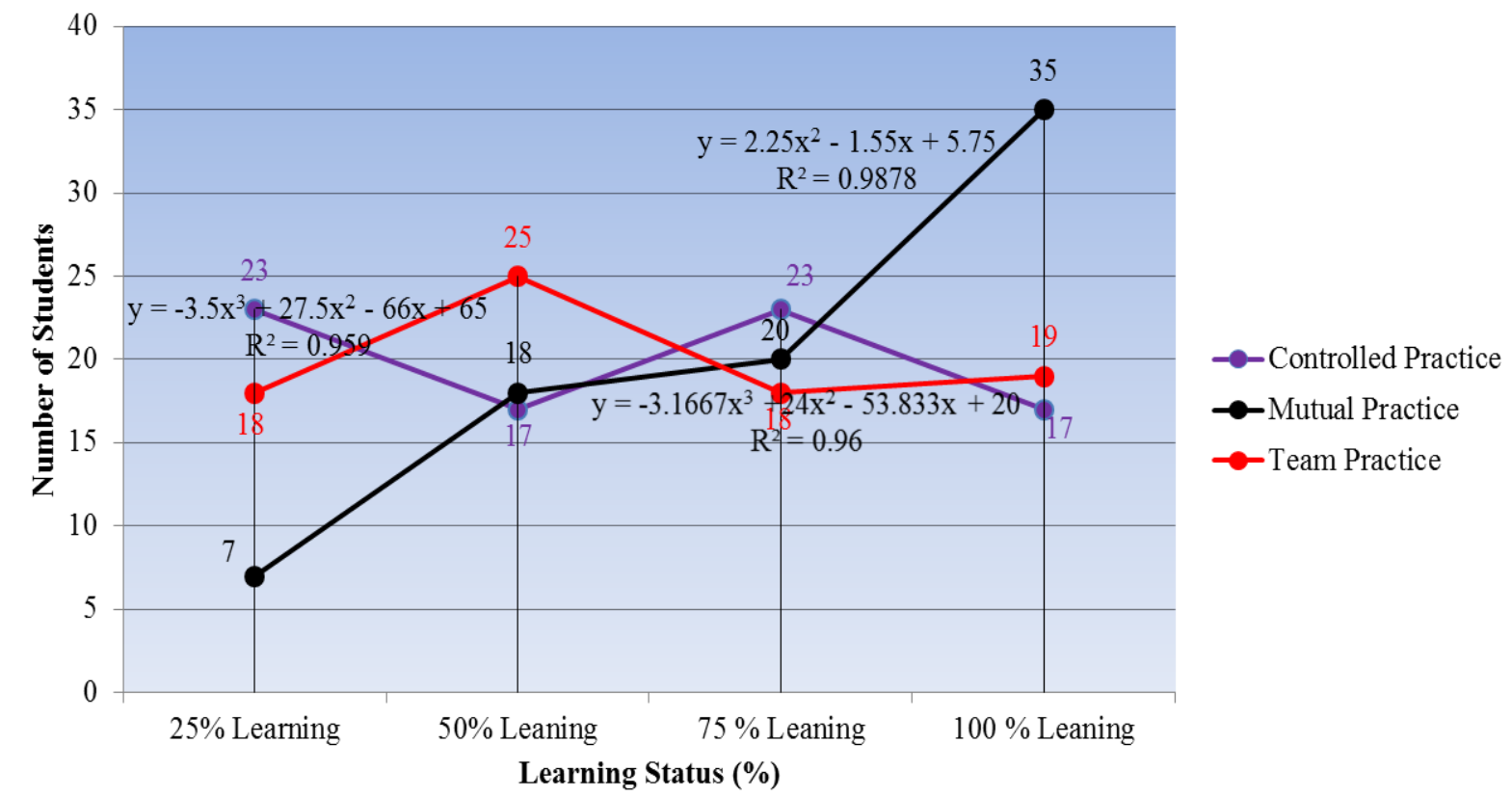

The digital model of the three practice methods revealed interesting results. The maximum number of students with $25 \%$ learning was $23(28.75 \%$ of total) for controlled practice method. The maximum number of students with $50 \%$ learning was $25(31.25 \%$ of total) for team practice. The maximum number of students with $75 \%$ learning was 23 (28.75\% of total) for controlled practice. The maximum number of students with $100 \%$ learning was $35(43.75 \%$ of total) for mutual practice method. The variation between the three methods was less at the $75 \%$ learning stage. The digital model of learning also provides representative equations and the value of coefficient of determination, $\mathrm{R}^{2}$ which is indication of the goodness of fit. The coefficient of determination value for mutual practice method is the highest $(0.9878)$ which means that the curve for mutual practice method represents the actual situation closely. To validate the relative standing of the three practice methods, the relative learning index (LI) were found for all the three methods. For this purpose, the representative equations were solved with Newton - Leibniz integration method. Representative equations for the three methods are given as equations (1), (2) and (3).

Learning Index of Controlled Practice Method, $\mathrm{LI}_{c p}=\int_{n=1}^{n=4}\left(-3.5 x^{3}+27.5 x^{2}-66 x+65\right) d x$

Where ' $n$ ' are categories of learning, which were four in this case i.e. $25 \%, 50 \%, 75 \%$ and $100 \%$. 


$$
\begin{aligned}
& \text { Learning Index of Mutual Practice Method, } \mathrm{LI}_{m p}=\int_{n=4}^{n=4}\left(2.25 x^{2}-1.55 x+5.75\right) d x \\
& \text { Learning Index of Controlled Practice Method, } \mathrm{LI}_{t p}=\int_{n=1}^{n=4}\left(3.1667 x^{3}-24 x^{2}+53.833 x-15\right) d x
\end{aligned}
$$

Solving equation (2) we get

$$
\text { Learning Index of Mutual Practice Method, } \mathrm{LI}_{m p}=\lim _{1 \rightarrow 4}\left[\frac{2.25 x^{3}}{3}-\frac{1.55 x^{2}}{2}+5.75 x+C\right]
$$

Where " $\mathrm{C}$ " is a constant to account for errors in data and variables. By putting the limits in equation we obtained the quantified value of rating for the losses in north zone.

Learning Index of Mutual Practice Method, $\mathrm{LI}_{m p}$

$$
=\left[\frac{2.25(4)^{3}}{3}-\frac{1.55(4)^{2}}{2}+5.75(4)+C\right]-\left[\frac{2.25(1)^{3}}{3}-\frac{1.55(1)^{2}}{2}+5.75(1)+C\right]
$$

Learning Index of Mutual Practice Method, $\mathrm{LI}_{m p}=[48-12.4+23+C]-[0.75-0.775+5.75+C]$

Learning Index of Mutual Practice Method, $\mathrm{LI}_{m p}=[58.60+C]-[5.725+C]$

Learning Index of Mutual Practice Method, $\mathrm{LI}_{m p}=[58.60+C-5.725-C]$

Learning Index of Mutual Practice Method, $\mathrm{LI}_{m p}=52.875$

\begin{tabular}{|c|c|c|c|c|c|}
\hline $\begin{array}{l}\text { Practice } \\
\text { Methods }\end{array}$ & $\begin{array}{l}\text { Learning } \\
\text { Categorie } \\
\text { s }\end{array}$ & Representative Equation & Trend & $\mathbf{R}^{2}$ & $\begin{array}{l}\text { Numerical } \\
\text { Value of } \\
\text { Indexes }\end{array}$ \\
\hline Controlled & 4 & $\begin{array}{c}\mathrm{LI}_{c p}=\int_{\substack{n=1 \\
n=4}}^{n=4}\left(-3.5 x^{3}+27.5 x^{2}-66 x\right. \\
+65) d x\end{array}$ & Cubic & 0.95 & $\mathrm{LI}_{c p}=30.615$ \\
\hline Mutual & 4 & $\mathrm{LI}_{m p}=\int_{\substack{n=1 \\
n=4}}\left(2.25 x^{2}-1.55 x+5.75\right) d x$ & Quadratic & 0.98 & $\mathrm{LI}_{m p}=58.875$ \\
\hline Team & 4 & $\begin{array}{c}\mathrm{LI}_{t p}=\int_{n=1}\left(3.1667 x^{3}-24 x^{2}+53.833 x\right. \\
-15) d x\end{array}$ & Cubic & 0.96 & $\mathrm{LI}_{t p}=40.92$ \\
\hline
\end{tabular}

Similarly, equations (1) and (3) were solved and the values obtained are shown in Table 2. These values of learning indexes validated student's opinion about the efficacy of different practice methods.

Table 2: Values of learning indexes obtained from Newton-Leibniz process

The highest numerical value of learning index was for mutual practice method, followed by team practice method and then the controlled practice method. The major reasons for effectiveness of mutual practice method are related to ease of learning. Students can make each other understand the phenomenon easily with frankness and informality. The second reason is that mutual practice method provides good opportunities for use of initiative and judgment by the students. Students do not get demotivated by correction of mistakes by another student. The guidance and direction by another student is informal and friendly.

Guidelines for Best Practical Training: Practice stage requires greater imagination and ingenuity by the teacher. The teacher has to institute a systematic process whereby the students are allowed to use their initiative and judgment and at the same time they are guided and mentored. Teacher needs to take care of necessary teaching aids so that the practice can be conducted in a meaningful way. And more importantly, teacher should be sure about the duration of practice depending on mental and physical capacity of students. Also, the number of practices depends on students learning capability. Based on the experience, following steps can help a teacher during the practice stage of learning. 
- Give specific instructions and guidance to students. Each student must understand the task. The lack of guidance will result in loss of focus and partial learning and consequently more time will be consumed.

- Set a standard but do not expect the learner to do a job which is still beyond his ability.

- Be realistic and give students practice as per their capability. Do not expect too much from the students initially.

- Don't be rigid in the practice. Let the student use their initiative and judgment. Make them involved with each other and mentor them on requirement basis only.

- Assist indirectly by brief corrections, a word of caution etc. Cut out unnecessary interruptions and involvement.

- If a student cannot realize the weakness in repeated practices, analyze his difficulty. At time, a student with good general intelligence may be clumsy and slow in practice stage. So, do not assume that the student is not learning.

- Reduce the amount of direct involvement. Practice again and again for accuracy.

- Noninvolvement and passiveness of the teacher in mutual practice technique does not mean his absence. Be present on the scene and keep noting the observations.

\section{Conclusion}

Making students skillful is a skill and a teacher needs to learn this skill. The study was conducted to know about the response of students about different practice methods and to determine the best method as per their opinion. The statistical analysis of students' opinion and digital analysis of practical learning process indicated that mutual practice is the most effective method of practice. It is because students learn better and fast when they are allowed to use their initiative and judgment. Teacher should act as guide and mentor during the practice stage of learning and allow the student to exercise their initiative and judgment.

\section{References}

Adams, S. (2002).Study of pedagogical effectiveness in learning, Research Report 365, DfES, London, 23-66.

Birdsall, N. (2005). Towards universal primary education: Investments, incentives, and institutions. European Journal of Education, 40, 337-349.

Broadhead, P. (2010). Play and learning in early childhood settings: Theory and practice, Sage, London, 203209.

Corts, D. P. (2000). Assessing undergraduate satisfaction with an academic department. College Student Journal, 34(3), 399-408.

Fabian, H. (2009). Development and learning for young children, Sage, London, 133-169.

Ives, B. (2001).A preliminary assessment of effectiveness in basic skills it training. MIS Quarterly, 25(4), 401426.

Jonassen, D. H. (2000). Towards a design theory of problem solving. Educational Technology Research \& Development, 48(4), 63-85.

Jones, H. (1999). Research framework and dimensions for evaluating the effectiveness of educational systems on learning outcomes. Journal of Research on Computing in Education, 32(1), 17-27.

Lin, I. M. (2002). Innovative teaching - starting from the professional ethics of teachers. Secondary Education, 4, 36-49.

Siraj Blatchford, I. (2008). Understanding the relationship between curriculum, pedagogy and progression in learning. Hong Kong Journal of Early Childhood Education, 7(2), 3-13.

Sylva, K. (2006). Assessing quality in the early years, Trentham Books Ltd, 36-76.

Teven, J. J. (1997). The relationship of perceived teacher caring with student learning and teacher evaluation. Communication Education, 46(1), 1-9.

Wu, C. S. (1987). Important concept and implementation strategy of creative teaching, Taiwan Education, 614.

Wood, E. (2005). Play, learning and the early childhood curriculum, Paul Chapman, London, 56-72. 